\title{
Open Standards in Scientific Communication and Publishing
}

\author{
ROBERT W. VAAGAN
}

\begin{abstract}
The paper takes as a starting point a recent EU Commission report on scientific publishing in Europe (Dewatripont et al 2006). In Norway, where a new system of documentation of scientific publishing was introduced in 2005, several of the recommendations in this report have already been anticipated. The Norwegian documentation system which has already proven controversial in parts of the research community and lacks parallells in other Nordic countries like Denmark and Sweden, is expected to have considerable consequences on Norwegian publishing patterns, such as increased use of electronic journals and of open standards such as Open Access and Open Source (Vaagan 2005). As e-publishing grows as part of the process of globalization, there is increasing awareness in many countries of ethical concerns in science and in scientific publishing, including the need for public access to publicly-funded research results. In this perspective, the paper links open standards in scientific communication and publishing to the principle of universality of science and to information ethics priorities identified by Capurro (2004). Qualitative methodology is used with critical \& typical case sampling (Patton 2002) of key policy documents as well as international articles on e-publishing 2000-2005, especially from $D$ $\mathrm{Lib}$ magazine. In conclusion, it is suggested that open standards such as Open Access and Open Source are likely to increase in scientific publishing in the future, both in Norway and in the EU.
\end{abstract}

Key Words: open standards, scientific communication and publishing, globalization, information ethics, universality of science

\section{Introduction}

In a recent EU Commission report on the economic and technical evolution of scientific publishing in Europe (Dewatripont et al 2006), a number of recommendations are made, including

- Guaranteed public access to publicly-funded research, at the time of publication and also long-term

- A "level-playing field" so that different business models in publishing can compete fairly in the market

- Ranking scientific journals by quality, defined more widely than pure scientific excellence, but also taking into account factors such as management of copyright, search of facilities and development 
- Developing pricing strategies that promote competition in the journal market

- Scrutinizing major mergers that may take place in the sector in the future

- Promoting the development of electronic publication, e.g. by eliminating unfavourable tax treatment of electronic publications and by encouraging public funding and public private partnerships to create digital archives in areas with little commercial investment.

Several of the underlying issues, particularly the concern with public access to publiclyfunded research, with the ranking of scientific journals and unfair VAT rules for electronic (but not print) publications, have been discusssed over the last couple of years also in Norway where a new system of documentation of scientific publishing was introduced in 2005. As I have argued elsewhere, there is considerable discussion in the Norwegian research community with this new system, particularly since it is used by the Ministry of Science and Education to measure scientific publishing in all Norwegian universities and colleges, and to reward (or penalize) institutions (Vaagan 2005).

\section{Norwegian Scientific Publishing}

There has long been a recognition in Norway that existing national and institutional systems of documenting Norwegian scientific publishing are inadequate. In a background report prepared for an OECD thematic review of Norwegian tertiary education, The Ministry of Education and Research in 2005 provided a whole range of statistics - but nothing on the volume and quality of scientific publishing (Ministry of Education and Research 2005a). The Norwegian Research Council usually quotes publications and citations mostly from the 8,700 full-text e-journals indexed in the Thomson ISI Web of Science. But there are currently at least 24,000 refereed, full-text e-journals in the world (Harnad 2005). The reliance on ISI is not only motivated by the excellent quality of ISI services (Thomson ISI 2004) and that many Norwegian researchers publish in ISI-indexed journals, but must in some measure also be ascribed to methodological "convenience sampling" (Patton 2002:241-42) linked with inadequacies of the two traditional national scholarly documentation systems in Norway - Bibsys/Forskdok and The Norwegian Social Science Data Service project database.

In 2003, the Norwegian Ministry of Education and Research (MER) commissioned The Norwegian Council for Higher Education (NCHE) to remedy this situation and prepare a feasibility study on a new national system for the documentation of scientific publishing by Norwegian researchers, to be based on bibliographic data and authority registers. The motivation was partly to encourage Norwegian researchers in all disciplines to be more ambitious regarding international publishing, which remains a key factor e.g. in the international ranking of universities (Cavallis \& Lindblad 2006). The NCHE appointed both an expert policy committee and a technical follow-up committee for the assignment, and the present author served as member 2003-2004 of the former committee. In the NCHE study (Norwegian Council for Higher Education 2004), several recommendations are made: To qualify as scientific, a publication must: a) present new insight, b) be in a form that allows the results to be verified or used in new research, c) be in a language and have a distribution that make it accessible to the majority of interested researchers, and d) have been published in a peer-reviewed publishing outlet (journal, series, book, and also website). Based on this definition, where all 
4 criteria must be met, authority registers have been generated in the form of data bases with more than 15,000 journals or serials with ISSN numbers (including all ISI-indexed electronic full-text journals) and more than 500 publishers of scientific titles with ISBN numbers. These have been identified and quality-controlled in consultation with appropriate Norwegian national discipline committees (nasjonale fagkomiteer). An estimated $20 \%$ of scientific publishing will take place at level 2, i.e. in the most prestigious journals, (including Nordicom Review) and serials with the most reputable publishers, as measured by impact factor. Level 2 publishing will be weighted significantly higher than level 1 publishing where the other $80 \%$ of normal scientific publishing is estimated to take place. Differential weighting, it is believed, will minimize changes in publishing patterns, such as more electronic articles and fewer printed monographs.

The MER, which provides more than $90 \%$ of the total funding of Norway's 6 universities, 5 specialized university institutions, 25 university colleges and 2 art schools, introduced in its budget for 2006 a unified system of only 4 indicators to measure and credit the research component ${ }^{1}$ in allocations to universities and state colleges: scholarly publishing, doctoral candidates, and financing from the European Union and Norwegian Research Council (Ministry of Education and Research 2005b).

Whereas the natural sciences, in particular medicine, have been favourable and even pushed for the new system, most opposition has emanated from the humanities $\&$ arts. In the natural sciences, publishing in English has long been the main way of scientific communication and publishing. In the humanities and social sciences, publishing tradition has been dominated by the printed article and monograph, mostly in Norwegian. Disciplines like history and law where most research is published in Norwegian, agonize about publishing in English, which the new system encourages. On 5 May 2006, Aftenposten carried a full-page protest signed by 223 professors in the humanities and social sciences in Norway against the perceived pressure of the new system to publish in English at the expense of Norwegian-language publishing. Yet defenders of the system refuted the protest in Aftenposten on 18 May 2006, and there are few signs that the authorities will revoke or modify the system. On balance, it remains a fact that while there are several Norwegian journals and publishers in the authority registers at level 1, there are only very few Norwegian journals - and no Norwegian publishers - at level 2. The system, therefore, clearly encourages English-language publishing, but does not rule out scientific publishing in Norwegian. The main "losers" in this new system are monographs in Norwegian, which explains much of the negative reaction from the humanities and social sciences.

In the humanities and arts, the ISI database has until recently been almost unknown: among the 8,700 ISI-indexed journals in the Web of Science, there have been three times as many journals in science as in the social sciences and humanities combined. The recommended authority registers have accordingly been expanded to more than 15,000 journals in which Norwegian researchers are known to have published. In comparison, The Thomson ISI Scientific Master Journal List presently includes 13,877 titles. Based on the "80-20" Bradford rule, Thomson ISI has selected and indexes "only" 8,700 journals, all electronic full-text journals, in its Web of Science list (McVeigh 2004; Thomson ISI 2004).

The authority registers are meant to be dynamic, i.e. journals and publishers can be changed based on nomination procedures through relevant professional committees. Bibliometrics indicate that the authority registers span almost $95 \%$ of the outlets where Norwegian researchers publish (Sivertsen 2003:85). When a Norwegian researcher registers his/her results in the most widely used institutional reporting system (FRIDA), 
these are verified against bibliographic data and authority registers. Only entries that are authenticated will be accepted as scientific publications.

Other forms of publishing that do not satisfy the 4 listed criteria of scientific publishing are classified as "dissemination" (formidling). Although dissemination is seen as essential and does generate money flows, it counts less in terms of scientific merit and reward.

Among several possible pitfalls, co-authorship will complicate matters and necessitate a distribution of credits among several authors and institutions. Co-authorship per se especially in medicine and the natural sciences, has come under attack in consequence of a recent scandal ${ }^{2}$, and also because the financing system allegedly encourages unwarranted co-authorship (Vogt \& Aas 2006). Author addresses and institutional affiliation(s) must be part of the bibliographic data. Who is "Norwegian" depends not on citizenship, but author address given in the original data when the publication was first registered. When fully operative, the system must be seen as legitimate by the research community, simulations are needed to visualize budgetary consequences, so implementation must take place in a predictable manner. Another likely outcome (already in evidence throughout 2005) has been disciplinary infighting to get monographs and journals up from level 1 to level 2, which generetas more money for publications due to the differential weighting. Moreover, the transparency of the system to commercial publishers and vendors makes it vulnerable to price hikes. Also, scientific publishing as an indicator in the international ranking of universities has recently been questioned (Cavallin \& Lindblad 2006). As I shall return to, there are also wider ethical issues that cause concern.

Collection development in Norway's 336 academic, research and special libraries is increasingly marked by electronic journals (Torras \& Vaagan 2006). Few Norwegian libraries have gone, or plan to go, e-only. The transition from the hybrid to the digital library is being hampered not only by inadequate government financing of The Norwegian Digital Library, but also by the fact that e-only subscriptions (but not print subscriptions) pay 25\% VAT (Hunstad 2005). As mentiond, this is also a problem in the EU.

Net-based publishing based on institutional self archiving and repositories in Norwegian universities and university colleges is so far limited. As elsewhere, digitization of older, physical collections is only starting up (Astle \& Muir 2002), and a Norwegian Digital Library is only in its infancy. Oslo University in 2003 initiated a policy designed to switch all publication from paper to electronic formats by 2007. Dissertations, BA and MA theses, serials, reports, monographs and videos will be available electronically, coordinated with international initiatives (Hagen, Dobratz \& Schirmbacher 2003). One hopes that researchers will deposit copies of their articles published in scientific journals. In time this may aggregate into an institutional Open Access repository also of scientific publications - possibly also to the appearance of institutional e-journals. Many Norwegian libraries want more Open Access involvement (Hunstad 2005). Björk (2004) argues that institutional repositories can be both primary channels (e.g. for Ph.D. dissertations) and secondary channels, but that secondary publication requires changes, e.g. financial reward for depositing metadata in the research base plus uploading of PDF copy. The Romeo project concluded that self-archiving is a realistic approach for academics, that $71 \%$ of publishers already accept some form of self archiving, and that intellectual property rights problems can be resolved (Gadd, Oppenhein \& Probets 2003). This now includes Elsevier, the world's largest publisher of STM journals.

Increased use of scholarly e-publishing also raises the issue of whether or not to choose proprietary or open source software. In 2005 the then Minister of Modernisa- 
tion encouraged a public sector switch (especially in local authorities and primary/secondary schools) from Microsoft to Linux, a policy his successor from October 2005 has continued. However, it remains to be seen how this will affect tertiary education, science and scholarly publishing.

On balance, the new MER budget model will have repercussions on scientific publishing, though it may be too early to say exactly how. As I have argued elsewhere, important determinants include advancement of open standards such as Open Access publishing and institutional OA repositories, improvement of quicker online peer-review systems, improved competence in Digital Rights Management, a switch to author payment systems, a shift from the use of proprietary to open source software, better awareness of information ethics, clearer institutional and governmental policies on e-publishing, and not least government readiness to adequately finance the long-planned Norwegian Digital Library (Vaagan 2005).

In a Nordic context, it should be noted that the system that has been adopted in Norway is being followed with interest by several other Nordic countries. In Sweden and Denmark, as in most countries, when researchers publish in excellent journals and with good publishers, this eventually will have a bearing on money flows at the institutional and/or personal level. Yet neither Denmark nor Sweden have considered emulating the Norwegian system of centrally planned, ministerial, budgetary rewarding of greater scientific publishing (Kladagis 2006; Jacobsson 2006).

In a European context, much will depend on to what extent the outlined recommendations in the EU Commission report are followed up. But as we have seen, several of the recommendations are consistent with some of the trends in Norwegian scientific publishing, e.g. public access, ranking of scientific journals, and concern with unfavourable VAT on electronic publications. Although the EU report does not recommend the inclusion of scientific publishing in a central budgetary model, the recommended ranking system of journals may in the future lead to some form of a "Norwegian" system of formalized authority registers of journals and publishers. The experiences presently being made in Norway will therefore be of interest not only to Sweden and Denmark, but perhaps also to other EU countries.

In the following, I shall limit the discussion to a consideration of open standards, particularly Open Access and Open Source, which have been raised both in the EU Commission report and in the Norwegian debate.

\section{Globalization, Open Standards, the Universality of Science and Ethics}

In his recent best-seller on globalization, Friedman (2005, 2006) advances 10 "flattening" forces that combine to form globalization. Among the ten forces, he attributes the greatest single impact to uploading. This consists of a broad range of electronic publishing (blogging, "citizen journalism", Wikipedia etc), including community-developed software made freely available on the Internet through open source software (e.g. Apache, Linux).

Friedman, though, does not elaborate his argument into a consideration of other aspects of open standards that are particularly relevant for scientific publishing, such as Open Science, Open Archives and Open Access. The relevance of these principles for scientific publishing have emerged over the last decade with increasing force (Björk 2004; Coyle 2004; Klang 2005; Lessig 2004, Vaagan \& Koehler 2004). 
Despite the flattening elements of globalization, research results are not yet freely and equitably available - due largely to protective commercial interests, copyrights and trademarks, intellectual property rights, commercial publishers and restrictions inherent especially in privately-funded research. Moreover, knowledge gaps and digital gaps in 2006 still effectively bar out roughly $85 \%$ of the world's population of 6,4 billion who are still not online (Computer Industry Almanac 2006). Although scientific publishing can be considered as the main channel of communication for science, it has so far largely been seen as too elitist for inclusion in mass communication research. The dissemination of science to the general public is not a priority in mass communication research (Bryant \& Myron 2004; McQuail, Golding \& de Bens 2005). Also, dissemination of science is hampered by inadequacies in science journalism (Hornmoen 2003).

We need perhaps to be reminded that research, more often than not, is a very competitive business, and it is illusory to think that e-g- a profit-based enterprise should jeopardise its market position by divulging what it considers as industrial secrets. The ongoing controversy between the EU Commission and Microsoft is perhaps the most pertinent case in point (Vaagan \& Koehler 2005). Still, for publicly-funded research open standards are fundamental e.g. to The International Council of Scientific Unions (ICSU). ICSU is an NGO founded in 1931, represents a global membership of 103 national scientific bodies and 27 international scientific unions. It has long advocated the principle of universality of science that embodies freedom of movement, association, expression and communication for scientists as well as equitable access to data, information and research materials (ICSU 2006). This policy is consistent with the open standard principles of Open Science, Open Archives, Open Access and Open Source.

Open standards have a distinct ethical dimension, as "knowledge gaps" and "digital gaps" among (and even within) countries remind us of. Although open standards in scientific communication and publishing have yet to make an impact on media ethics as a research priority (Nordenstreng 2000; Gunkel \& Hawhee 2003), some advances are underway in the field of information ethics. Thus Capurro (2004) argues that reflection based on information ethics must embrace cultural as well as philosophical-historical dimensions, and consider the following issues a) the development of moral conditions in the information field, especially in global digital networks; b) reveal and criticize information myths, analyse power relations that decide information issues; c) lay open concealed inconsistencies in theoretical and practical language norms; and d) survey the development of information ethics issues. All of these four issues converge when we consider the open standards of Open Access and Open Source. An Open Access and Open Source perspective can thus contribute to heightened moral reflection on global digital networks (Capurro's first point), improved understanding of power relations expressed as the digital divide (Capurro's second point), greater clarity regarding the meaning of "free" software and "free" information (Capurro's third point). In sum, these points add up to an overview (Capurro's fourth point) that gives heightened appreciation of open standards.

\section{Open Access (OA)}

As defined by one of its leading proponents, Stevan Harnad, Open Access means "immediate, permanent, free online access to the full text of all refereed research journal articles (2.5 million articles a year, published in 24,000 refereed journals, across all disciplines, languages and nations)" (Harnad 2005). OA involves 4 channels: a) elec- 
tronic, refereed scientific periodicals; b) research-specific archive (e-print) servers; c) institutional repositories of individual universities and d) self-posting on author's home pages (Björk 2004).

The Open Access Initiative (OAI) has ideological affinities with the philosophies of the Free Software Foundation from 1983 and the Open Source Initiative (OSI) from 1997. Both OA, FSF and OSI see the user as the major beneficiary. OAI has been spurred on by the serials crisis, SPARC, The Budapest Open Access Initiative, and the Berlin Declaration on Open Access to Knowledge in Science and the Humanities. During the 1990s, hundreds of OA journals appeared, based on idealism and commitment from OA adherents. Nonetheless, roughly half of these have disappeared and successes like First Monday are few. It has proven difficult to compete with traditional subscription-based commercial journals which continue to dominate. Still, OA journals are making their impact felt, and the Directory of Open Access Journals maintained by Lund University Libraries now counts 2,340 titles. Among the 8,700 journals on the Thomson ISI Web of Science list, 239 are OA journals (Thomson ISI 2004; McVeigh 2004; Pringle 2004), and OA proponents argue that OA articles are cited 3,36 times more than articles in commercial journals (Harnad \& Brody 2004). The OAI now comprises a variety of repositories, search engines, reference linking and harvesting systems, e.g. Directory of Open Access Journals, BioMed Central, PubMed Central, FreeMedical Journals.com, Public Library of Science, SciX, LOCKSS, arXiv, Open Archives Initiative, OAI-PMH (Open Access Initiative - Protocol for Metadata Harvesting), SPARC, CrossRef, OAIster.

OA publishing means a shift from a "pay-to-use" to a "pay-to-produce" model, i.e. instead of the user being made to pay through subscription or access fees, the cost is transferred to the producer (the author, institution or provider of the publication) to sustain open access for all online users. This is not a new development with the Internet, on the contrary publishing history illustrates the use of both models (Kaser 2000). The cost transfer from user to provider is of course most appealing to users, especially those who can ill afford expensive subscriptions or access fees, especially in poorer countries and regions. The cost transfer means that for OA publishing to flourish, new business models must be developed to recover costs, since OA publishing cannot be sustained for a long time only by the idealism and commitment of involved developers. To a considerable extent the cost transfer is an ethical issue, and highly relevant for the analysis of the digital divide.

Here it must be remarked that OA is too often limited to a discussion of business models (Hardy, Oppenheom \& Ribbert 2002; King 2004; Kaser 2004; Wilson 2004), cost per article reading and return on investment (Montgomery \& King 2002; Holmström 2004ab), legal and financial issues, as well as considerations related to ITinfrastructure, indexing services and standards, academic reward, marketing and critical mass (Björk 2004). It is often neglected that the underlying philosophy is ethical and ideological. Open Access is essentially a protest against hegemonic and profit-based publishing structures. As I have discussed elsewhere, in terms of media \& communication theory OA represents a shift to symmetrical and more equitable dialogic and polyphonic relations (Vaagan 2006). The OA and OS movements are gaining momentum internationally, and several key research funding agencies in the US and the UK now require copies of articles deposited in open institutional archives. In Norway, it can be added that $\S 100$ in the Norwegian constitution, which deals with Freedom of expression, was amended from October 2004 to include a new formulation making it a state respon- 
sibility to provide an "open" and "enlightened" public debate. Adherents of OA and OS in Norway will no doubt use this formulation to advance their own positions. As an information ethics research issue, the OA component in scientific publishing is clearly relevant, both in Norway and elsewhere.

The extent and pace of this probable development needs to be analyzed in much greatre detail than I have attempted here, through individual /case/disciplinary/country studies and comparative research.

\section{Open Source Initiative (OSI)}

The open source idea is basically that software evolves faster and becomes more stable as more people work on it. Code-sharing and co-development is usual in the UNIX world, which contrasts with the corporate secrecy of commercial developers. To use the Open Source trademark, software developers must distribute their software and its source for free. As e-publishing intensifies with the process of globalization, the choice of relying on market-dominating proprietary software like Microsoft products or open source software like Linux becomes more apparent. The choice has both ideological/ ethical and financial aspects.

In Norway, the former Minister of Modernisation, as noted, encouraged a public sector switch (especially in local authorities and schools) from Microsoft to Linux. This has been partly motivated by allegations that Microsoft had entered into covert and market-distorting agreements with secondary schools to only use Microsoft products. But it has also been motivated by the paradox that in affluent Norway, a considerable number of Norway's 434 local authorities in recent years have been technically bankrupt and have been placed under direct state financial and administrative supervision. Several Norwegian local authorities and counties already rely on software packages freely available in Norwegian from OpenOffice.org. All Norwegian public libraries now disseminate CDs with free software comparable with proprietary standards such as Word and Outlook, which can be used either on Linux, Mac, Windows or Solaris platforms. This is seen as a guarantee of public access and participation which again are prerequisites for a viable democracy. Similarly, in a Nordic context, The Nordic Council has made available on nordicos.org more than 30 free software products adapted to individual skill levels, operating systems and programs. A shift to open source and public domain software is therefore not only ideologically and ethically motivated (cf. Klang 2005 and his term "ethics of software") but also financially motivated, similar to what is happening in many other affluent countries and regions (e.g. the UK, Germany, Denmark, California).

The objectives of the Free Software Foundation (FSF) set up by Richard Stallman in 1983 to create a software commons, were to promote the computer users' right to use, study, copy, modify and redistribute computer programs. FSF's philosophy was set out in the so-called "four freedoms" in the General Public Licence (GPL). It was argued that software must not be under the control of commercial developers and vendors because these would limit usage and only provide necessary infrastructure at a price. The Open Source Initiative from 1997-98 was inspired by Raymond (1997, 2001) who first drew the attention of commercial software vendors to the open source idea. OSI is a non-profit organization and an alternative to FSF, less moralistic and less negative to commercial developers and vendors. OSI's compromise meant that open source products such as Official Red Hat Linux Software, are sold and buyers are paying for warranty and tech- 
nical support. Apparently some open source idealists agree with Kaser (2000) that free information is an illusion: there is always a cost for someone. The economic and political success of OSI is seen in that proprietary software is increasingly being challenged by open standards and public domain software, both in the private and public sector. Digital Rights Management (ironically referred to as "Digital Restrictions Management") is emerging as an increasingly important instrument to secure commercial developers' interests (Ianella 2000; Coyle 2004; Lessig 2004; Klang 2005; Vaagan 2005). Yet Klang concludes that the FSF-OSI rivalry has damaged both. He argues that the increase in open source software is outweighed by fewer debates over some basic philosophical issues: "....we have lost the most important element of the debate - who should own the most fundamental elements of our infrastructure" (Klang 2005). If we accept this, we also accept the relevance of Capurro's arguments.

Van de Sompel, Payette, Erickson, Lagoze \& Warner (2004) who address the need for a next-generation system of scholarly communication, observe that there exists no generally accepted information model for the domain of scientific publishing. They propose the development of information models, process models and related protocols to enable interoperability between existing repositories, information stores and services. Although information ethics is not a part of their discussion, it is clear that also their projections suggest that both OA and OSI have considerable scope.

As for scientific publishing in Norway and possibly also in other Nordic and European countries, the same tentative conclusion relating to OA above can be drawn: In the years to come, the use of OS software relative to proprietary software in the research communities will increase, and will be an important element in advancing open standards in scientific publishing. The extent and pace of this process needs to be followed in more detailed research, both individual case studies and comparative analysis.

\section{Conclusion}

Both in the EU and in Norway there are debates and experimentations regarding scientific communication and publishing, as the process of globalization unfolds and electronic publishing gathers pace. A common concern addressed in this paper, is that publicly funded research results be freely accessible to a widest possible spectrum of society. The underlying motivation has both ideological, ethical but also financial aspects. To achieve this goal of widest possible public access and the ideal of universality of science, several steps are necessary, of which this paper has concentrated on open standards such as Open Access and Open Source. Looking ahead, it is projected that scientific publishing, the main channel of communication for science, both in Norway and in the EU, will become increasingly characterized by the use of Open Access and Open Source, although the extent, pace and context need to be clarified through further research.

\section{Notes}

1. Allocations to tertiary education institutions from the Ministry of Education and Research have until recently been composed of 3 components: a) a basic component (57-63\%), b) teaching/study points $(22-31 \%)$ and c) research (6-22\%). The exact percentage and mix has largely depended on institutional status as university or state college. The research component has been measured through a variety of indicators which from 2005 have been reduced to 4: scholarly publishing (a new indicator), doctoral candidates, financing from the Norwegian Research Council and European Union 
research grants. In addition, a fourth component - dissemination (formidling) - is to be introduced from 2006-2007. For details cf. Ministry of Education and Research 2005a, esp. tables 7.6 and 7.8.

2. In January-February 2006, Dr. Jon Sudbø, Associate Professor, a Norwegian medical researcher, employed by the Comprehensive Cancer Center (Radiumhospital) and by The Medical Faculty of The University of Oslo, admitted to having fabricated data in several co-authored articles published 20042005 in leading journals like Lancet, Journal of Clinical Oncology and The New England Journal of Medicine. In many cases he had listed colleagues as co-authors without their knowledge. An investigative inquiry exhonorated his co-authors of complicity but found that most of his research, including his doctoral dissertation, was fraudulent.

\section{References}

Astle, P. \& Muir, A. (2002) 'Digitization and Preservation in Public Libraries and Archives', Journal of Library and Information Science, 34(2), 67-79.

Bryant, J. \& Miron, D. (2004) “Theory and Research in Mass Communication', Journal of Communication, 54, 662-704

Björk, B-Chr. (2004) 'Open Access to Scientific Publications - An Analysis of the Barriers to Change?', Information Research - An International Electronic Journal, 9 (2) Retrieved 10.8.06 from http:// informationr.net/ir/9-2/paper170.html

Capurro, R. (2004) 'Informationsethick - Eine Standortbestimmung', International Journal of Information Ethics, 1 (06/2004) Retrieved 10.8 .06 from http://container.zkm.de/ijie/ijie/no001/ ijie_001_02_capurro.pdf

Cavallin, M. \& Lindblad, S. (2006) Världsmästerskap i vetenskap? En granskning av internationella rankinglistor och deres sätt att hantera kvaliteter hos universitet. Göteborgs universitetet, Dnr. GII530/06. Retrieved 10.8.06 from http://www3.gu.se/rapporter/2006/060210_Rankinglistor.pdf

Computer Industry Almanac Inc. (2006) Retrieved 12.8.06 from: http://www.c-i-a.com/pr0106.htm

Coyle, K. (2004) 'The 'Rights', in Digital Rights Management', D-Lib Magazine, 10 (9) Retrieved 10.8.06 from http://www.dlib.org/dlib/september04/coyle/09coyle.html

Dewatripont, M. et al (2006) Study on the Economic and Technical Evolution of the Scientific Publication Market in Europe. Final report, January 2006. Commissioned by Directorate-General for Research, European Commission. Brussels. Retrieved 10.8.06 from http://europa.eu.int/comm/research/sciencesociety/pdf/scientific-publication-study_en.pdf

Directory of Open Access Journals (2006) Retrieved 10.8.06 from http://www.doaj.org/

Electronic Frontier Norway (2006) Retrieved 10.9.06 from http://efn.no/eng-index.html

Friedman, Th.L. $(2005,2006)$ The World is Flat. The Globalized World in the Twenty-First Century. London: Penguin Books

Free Software Foundation (2006) Retrieved 10.8.06 from http://www.fsf.org/

Gadd, E.; Oppenheim, C. \& Probets, S. (2003) 'The Intellectual Property Rights Issues Facing SelfArchiving. Key Findings of the RoMEO Project', D-Lib Magazine, 9(9) Retrieved 10.8.06 from http:/ /www.dlib.org/dlib/september03/gadd/09gadd.html

Gunkel, D.J. \& Hawhee, D. (2003) 'Reformatting Ethics', Journal of Mass Media Ethics, 18 (18.3/18.4) Retrieved 10.8.06 from http://www.jmme.org/

Hagen, J.H. \& Dobratz, S. \& Schirmbacher, P. (2003) 'Electronic Theses and Dissertations Worldwide', DLib Magazine, 9 (7/8) Retrieved 10.8.06 from http://www.dlib.org/dlib/july03/hagen/07hagen.html

Hardy, R.; Oppenheim, C. \& Rubbert, I. (2002) 'Pricing Strategies and Models for the Provision of Digitized Texts in Higher Education', Journal of Information Science, 28 (2), 97-110.

Harnad, S. (2005) 'The Implementation of the Berlin Declaration on Open Access', D-Lib Magazine, 11(3) Retrieved 10.8.06 from http://www.dlib.org/dlib/march05/harnad/03harnad.html

Holmström, J. (2004a) 'The Cost per Article Reading of Open Access Journals', D-Lib Magazine, 10(1) Retrieved 10.8.06 from http://www.dlib.org/dlib/january04/holmstrom/01holmstrom.html

Holmström, J. (2004b)'The Return on Investment of Electronic Journals - It is a Matter of Time', D-Lib Magazine, 10(4) Retrieved 10.8 .06 from http://www.dlib.org/dlib/april04/holmstrom/ 04holmstrom.html

Hornmoen, H. (2003) Forskningsjournalistikk i en brytningstid: kritisk diskursanalyse av amerikansk 'science journalism' på 1990-tallet. Acta Humaniora (Ph.D. dissertation) Historisk-filosofisk fakultet, Universitetet i Oslo, Oslo:Unipub

Hunstad, S. (2005) Kartlegging av erfaringer med bruk av konsortieavtaler. Brodd. Available online (in Norwegian) from http://norskdigitaltbibliotek.no/archives/RapportBRODDlisens.pdf 
Ianella, R. (2001) 'Digital Rights Management (DRM) Architectures', D-Lib Magazine, 7(6) Retrieved 10.8.06 from http://www.dlib.org/dlib/june01/iannella/06iannella.html

ICSU - International Council of Scientific Unions (2006) Retrieved 10.8.06 from http://www.icsu.org/ index.php

Kaser, R.T. (2000) 'If Information Wants to be Free...Then Who's Going to Pay for It?', D-Lib Magazine, 6(5) Retrieved 10.8.06 from http://www.dlib.org/dlib/may00/kaser/05kaser.html

King, D. (2004) 'Should Commercial Publishers be Included in the Model for Open Access through Author Payment?', D-Lib Magazine, 10(6) Retrieved 10.8.06 from http://www.dlib.org/dlib/june04/king/ 06king.html

Klang, M. (2005) 'Free Software and Open Source. The Freedom Debate and its Consequences', First Monday, 10(3) Retrieved 10.8.06 from http://www.firstmonday.org/issues/issue10_3/klang/index.html

Lessig, L. (2004) Free Culture: How Big Media Uses Technology and the Law to Lock Down Culture and Control Creativity. New York, NY: Penguin Press. Retrieved 10.8.06 from http://www.bib.hive.no/ tekster/ekstern/lessig/freeculture.pdf

McQuail, D., Golding, P \& de Bens, E. (eds.) (2005) Communication Theory \& Research. An EJC Anthology. London:Sage.

McVeigh, M.E. (2004) 'Open Access Journals in the ISI Citation Databases: Analysis of Impact Factors and Citation Patterns. A Citation Study from Thomson Scientific'. Thomson Corporation. Retrieved 10.8.06 from http://www.isinet.com/media/presentrep/essayspdf/openaccesscitations2.pdf

Ministry of Education and Research (2005a) OECD Thematic Review of Tertiary Education. Country Background Report for Norway. Norwegian Background Report. Oslo: Ministry of Education and Research. Retrieved 10.8.06 from http://www.dep.no/kd/english/doc/reports/045061-220008/dokbn.html

Ministry of Education and Research (2005b) St.melding $n r .20$ (2004-2005) Vilje til forskning. Oslo: Ministry of Education and Research

Ministry of Government Administration and Reform (2006) Retrieved 10.8.06 from http://odin.dep.no/mod/ english/bn.html

Montgomery, C.H. \& King, D.W. (2002) 'Comparing Library and User Related Costs of Print and Electronic Journal Collections. A First Step Towards a Comprehensive Analysis', D-.Lib Magazine, 8 (10) Retrieved 10.8.06 from http://www.dlib.org/dlib/october02/montgomery/10montgomery.html

Nordenstreng, Kaarle (2000) 'The Structural Context of Media Ethics: How Media Are Regulated in Democratic Society', in Bart Pattyn (ed.) Media Ethics: Opening Social Dialogue. Leuven: Peeters, 69-86.

Nordicos (2006) Retrieved 11.8.06 from http://www.nordicos.org/

Norwegian Council of Higher Education (2004) Vekt på forskning. Nytt system for dokumentasjon av vitenskapelig publisering. Innstilling fra faglig og teknisk utvalg til UHR. Avgitt 12.11.04. Oslo: Norwegian Council of Higher Education

Open Office (2006) Retrieved 11.8.06 from http://www.openoffice.org/

Open Science Project (2006) Retrieved 10.8.06 from http://www.openscience.org/blog/

Open Source Initiative (2006) Retrieved 10.8.06 from http://www.opensource.org/

Patton, M.Q. (2002) Qualitative Research \& Evaluation Methods. London:Sage

Pringle, S. (2004) 'New Opportunities in Open Access', Thomson ISI. Retrieved 10.8.06 from: http:// thomsonscientific.com/news/newsletter/2004-11/8254463/

Raymond, Eric S. (1997, 2001) The Cathedral and the Bazaar. Musings on Linux and Open Source by an Accidental Revolutionary. Beijing: O'Reilly

Sivertsen, G. (2003) 'Norsk vitenskapsindeks. Bibliotekenes bidrag til dokumentasjon og formidling av norsk forskning?', Synopsis, 2 , 80-88.

Thomson ISI (2004) The Thomson Scientific Journal Selection Process. Retrieved 10.8.06 from http:// scientific.thomson.com/free/essays/selectionofmaterial/journalselection/

Torras, M-C. \& Vaagan, R. (2006) 'Websites and Internationalisation. A Survey of Norwegian Academic, Research and Special libraries', Libri, 56 (1) March 2006, 28-37

Vaagan, R. (2006) 'Open Access and Bakhtinian Dialogism', in Martens, B \& Dobreva, M. ELPUB2006. Digital Spectrum: Integrating Technology and Culture. Proceedings of the 10th International Conference on Electronic Publishing held in Bansko, Bulgaria 14-16 June 2006, 165-174.

Vaagan, R. (2005) 'Trends in Norwegian Scholarly Publishing', in Dobreva, M. \& Engelen, J. (eds.) (2005) From Author to Reader. Challenges for the Digital Content Chain. Proceedings of the 2005 ELPUB Conference. Katholieke Universiteit Leuven, 8-10 June 2005. Peeters Publishing, Leuven, 83-89. 
Vaagan, R. \& Koehler, W. (2005) 'Intellectual Property Rights vs. Public Access Rights. Ethical Aspects of the DeCSS Decryption Program', Information Research - An International Electronic Journal, 10(3) Retrieved 10.8.06 from http://informationr.net/ir/10-3/paper230.html

Van de Sompel, H.; Payette, S.; Erickson, J.; Lagoze, C. \& Warner, S. (2004) 'Rethinking Scholarly Communication ', D-Lib Magazine, 10 (9) Retrieved 10.8.06 from http://www.dlib.org/dlib/september04/vandesompel/09vandesompel.html

Vogt, Y. \& Aas, H. (2006) 'Utrolig rekord: 383 medforfattere', Apollon, 1, 6-7.

Wilson, B. (2004) “The Changing Landscape of Scholarly Publishing', D-Lib Magazine, 10 (7/8) Retrieved 10.8.06 from http://www.dlib.org/dlib/july04/07editorial.html

\section{Other Sources}

Grete Kladagis, Chief consultant, Danish Agency for Science, Technology and Innovation, Copenhagen, Denmark (telephone interview 29 June 2006).

Carl Jacobsson, Head of Research Policy Analysis, The Swedish Research Council, Stockholm, Sweden (email dated 29 June 2006)

ROBERT W. VAAGAN, Ph.D., Associate Professor, Faculty of Journalism, Library and Information Science, Oslo University College, PO Box 4, St.Olavs plass, N-0130 Oslo, robert-wallace.vaagan@jbi.hio.no 